\title{
Materials Advances
}

\section{CORRECTION}

View Article Online

View Journal I View Issue

\section{D) Check for updates \\ Cite this: Mater. Adv., 2020, \\ 1,2542 \\ Correction: High intrinsic activity of the oxygen evolution reaction in low-cost $\mathrm{NiO}$ nanowall electrocatalysts}

\author{
Salvatore Cosentino, ${ }^{\text {ab }}$ Mario Urso, ${ }^{\text {ab }}$ Giacomo Torrisi, $^{\text {ab }}$ Sergio Battiato, ${ }^{\text {ab }}$ \\ Francesco Priolo, $^{\mathrm{ab}}$ Antonio Terrasi ${ }^{\mathrm{ab}}$ and Salvo Mirabella ${ }^{\mathrm{ab}}$
}

DOI: $10.1039 / \mathrm{d} 0 \mathrm{ma} 90028 \mathrm{a}$

Correction for 'High intrinsic activity of the oxygen evolution reaction in low-cost $\mathrm{NiO}$ nanowall

rsc.li/materials-advances electrocatalysts' by Salvatore Cosentino et al., Mater. Adv., 2020, DOI: 10.1039/d0ma00467g.

The authors regret that there was an error in the affiliations given for Sergio Battiato and Antonio Terrasi. The correct affiliations are as listed here.

The Royal Society of Chemistry apologises for these errors and any consequent inconvenience to authors and readers.

${ }^{b}$ Dipartimento di Fisica e Astronomia “Ettore Majorana”, Università di Catania, Via S. Sofia 64, 95123 Catania, Italy. E-mail: mario.urso@dfa.unict.it 